\title{
Leflunomide inhibits the apoptosis of human embryonic lung fibroblasts infected by human cytomegalovirus
}

\author{
Ren $\mathrm{Qi}^{1}$, Zeng Hua-Song ${ }^{1 *}$ and Zeng Xiao-Feng ${ }^{2}$
}

\begin{abstract}
Background: The immunomodulatory drug leflunomide (LEF) is frequently used for treating human cytomegalovirus (HCMV), but its antiviral mechanism is still unclear. In this study,we therefore investigated the effects of the active LEF metabolite A771726 on the HCMV lifecycle in human embryonic lung fibroblasts. We clarified the mechanism of LEF antiviral infection, and provide a new way to treat immune dysfunction patients with HCMV infection.
\end{abstract}

Methods: The experiment was divided into four groups: the control group, the HCMV group, the ganciclovir + HCMV group as well as the LEF + HCMV group. MTT was usedfor assessment of the cell inhibitory rate. Apoptosis was measured by staining with fluorescein isothiocyanate Annexin $\vee$ and propidium iodide. Statistical significance was determined by paired $t$-test using SPSS software.

Results: The results of the study showed that cell proliferation was significantly inhibited by HCMV at 24 hours and 48 hours. With increasing HCMV concentration, the value-added inhibition of the cells was significantly decreased compared with the control group, and was statistically significant $(P<0.01)$. Ganciclovir can increase proliferation of cellsinfected with HCMV; compared with the control group it was statistically significant $(P<0.05)$. Meanwhile, with LEF treatment cell proliferation was significantly improved at 24 hours and 48 hours, with statistical significance $(P<0.05)$. The apoptosis rate of human embryonic lung fibroblasts infected with HCMV increased significantly at 24 hours, 48 hours and 72 hours, and as time goes on the apoptosis rate increases statistically significantly $(P<0.01)$ compared with the control group The apoptosis rate of theHCMV infection group decreased by adding LEF, and was statistically significant $(P<0.05)$.

Conclusions: In this studywe show that LEF is an exciting new drug for cytomegalovirus infection. LEF significantly inhibited HCMV infection-induced apoptosis and proliferation, playing an important role in the treatment of patients infected by HCMV. In this study we explored the potential usefulness of LEF for cytomegalovirus infection and found it to be a cost-effective new treatment for cytomegalovirus infection that deserves further study.

Keywords: Leflunomide, Human cytomegalovirus, Human embryonic lung fibroblast, Apoptosis

\footnotetext{
* Correspondence: huasongz@gmail.com

${ }^{1}$ The Department of Pediatric, Allergy, Immunology and Rheumatology, Guangzhou Women and Children's Medicial Center, Guangzhou Medical University and First Clinical Medical College, Jinan University, China Full list of author information is available at the end of the article
} 


\section{Background}

Leflunomide (LEF) is an immunosuppressive drug used clinically for the treatment of transplantation patients. Interestingly, besides its immunosuppressive activities, LEF can interfere with the replication of many viruses. Human cytomegalovirus (HCMV) belongs to the $\beta$ subfamily of the herpes virus, and is the most common pathogen of utero and postnatal infection, which can cause stillbirth, fetal malformation, miscarriage, developmental retardation and abnormal liver function. HCMV is the major pathogen of congenital malformations, growth retardation of the nervous system, hearing and visual impairment, blood system diseases, infant hepatitis and other serious diseases. HCMV infections are also common causes for people who have low immune function, such as organ transplant or AIDS patients. HCMV can replicate in the human embryonic lung fibroblasts. The mechanism of apoptosis inducted by HCMV infection is not clear. Another study showed that HCMV infection can cause clinical disease and apoptosis, which are closely related to each other [1]. As cell physiological death, apoptosis play an important role in reducing aging and maintaining the balance of the body, but when the cell undergoes abnormal apoptosis it can cause a variety of diseases. In recent years, the study of HCMV and cell apoptosis has made great progress. The relationship between HCMV and apoptosis is more complexHCMV can inhibit cell apoptosis or promote apoptosis in the infection body [2]. The study found that the early stages of HCMV infection manifested as inhibition of apoptosis, which provided sufficient time for HCMV in cell proliferation [3]. With extension of the time of infection, however, the inhibition of apoptosis was changed by the promotion of apoptosis, which can cause loss of cell function and a number of pathological and clinical diseases. The higher the dose of HCMV infection, the sooner the cell mediated apoptosis [4]. LEF is a novel immunosuppressant, formation of the active metabolite A771726 playing a role in the body. Treatment with LEF A771726 may counteract the riskof enhancing HCMV replication in infected patients.

\section{Methods}

\section{Cell culture}

The cells were obtained from Zhongshan University (Ethical approval was given by the medical ethics committee of Sun Yat-sen University with the following reference number: SYXK20070081), and were maintained in 1640 medium, supplemented with $10 \%$ fetal calf serum and $1 \times 10^{5} \mathrm{U} / \mathrm{l}$ penicillin, and treated with the LEFHCMV and ganciclovir (GCV). The experiment was divided into four groups: the control group, the HCMV group, the GCV + HCMV group, as well as the
LEF + HCMV group. The control group included 0.02\% DMSO RPMI 1640, the HCMV group included HCMV, the GCV + HCMV intervention group included GCV and HCMV, and the LEF + HCMV intervention group included LEF and HCMV. Cells were then incubated at $37^{\circ} \mathrm{C}$ with a humidified atmosphere of $5 \% \mathrm{CO}_{2}$ in air. The above experimentwas performed three times.

\section{Assessment of inhibitory rate}

MTT was used to assessthe cell inhibitory rate. Cell suspensions were placed in triplicate in 96-well culture plates at 10,000 cells $/ 100 \mu \mathrm{l}$ per well. Cells were incubated for 96 hours at $37^{\circ} \mathrm{C}$ and $100 \mu \mathrm{l}$ MTT solution was added to each well. Cells were then incubated at $37^{\circ} \mathrm{C}$ for a further 4 hours. The plates were read on an automatic plate reader at a wavelength of $570 \mathrm{~nm}$ and the background absorbance measured at $690 \mathrm{~nm}$ was subtracted.

$$
\begin{aligned}
\text { Inhibitory rate }(\%)= & (\text { experimental group } / \text { control group }) \\
& \times 100 .
\end{aligned}
$$

The above experiments were repeated three times.

\section{Assessment of apoptosis}

Cells grown under growth-restrictive conditions were plated at a density of $1 \times 10^{6} / \mathrm{ml}$ and allowed to attach to tissue culture plates for 24 hours. Cells then were incubated with medium that contained $10 \%$ fetal bovine serum in the presence or absence of HCMV. LEF or GCV was added to the medium after 1 hour. The percentage of apoptotic cells was assessed, and cells were harvested at 24 hours and 48 hours. Apoptosis was measured by staining with fluorescein isothiocyanateAnnexin V and propidium iodide ((Sigma-Aldrich, Guangzou, Guangdong, China)). We then added $500 \mu \mathrm{l}$ cell suspension liquid to $5 \mu \mathrm{l}$ fluorescein isothiocyanateAnnexin $\mathrm{V}$ and $5 \mu \mathrm{l}$ propidium iodide, avoiding light at $4^{\circ} \mathrm{C}$ for 10 minutes. Absorbance was recorded at an excitation wavelength of $448 \mathrm{~nm}$, collecting 10,000 cellsfor each sample specimen. The cell apoptosis rate was then measured using the relevant software. The experiment was repeated three times.

\section{Statistical analysis}

Statistical significance of differences in measured variables between controls and treated groups was determined by paired $t$ test using SPSS for Windows V.13.0 (SPSS, Chicago, IL, USA). $\leq 0.05$ was considered statistically significant. 


\section{Results}

Inhibitory effect of leflunomide on human embryo lung cells infected with HCMV

The results of this study showed that cell proliferation was significantly inhibited by HCMV at 24 hours and 48 hours (see Table 1). With increasing HCMV concentration, the value-added inhibition of cells was significantly decreased compared with the control group andwas statistically significant $(P<0.01)$. GCV can increase proliferation of cells infected with HCMV, statistically significantly $(P<0.05)$ compared with the control group. Meanwhile, with LEF treatment the cell proliferation was significantly improved at 24 hoursand 48 hours, with statistical significance $(P<0.05)$. Results are shown in Figures 1, 2 and 3.

\section{Effect of leflunomide on the proliferation of human embryonic lung cells}

The final concentration of LEF was divided into three separate groups $40 \mathrm{~g} / \mathrm{ml}, 20 \mathrm{~g} / \mathrm{ml}$, and $5 \mathrm{~g} / \mathrm{ml}$. The effect of human fetal lung cell proliferation at the different doses of LEF was still significant $(P<0.05)$.

\section{Apoptosis detection}

The apoptosis rate of human embryonic lung fibroblasts infected with HCMV increased significantly at 24 hours, 48 hours and 72 hours, and as time goes on the apoptosis rate increases; compared with the control group it was statistically significant $(P<0.01)$. The apoptosis rate of the HCMV infection group decreased by adding LEF, and was statistically significant $(P<0.05)$. See Figures 4 and 5 .

\section{Discussion}

Cytomegalovirus (CMV) is one of the most important infections in the immunosuppressed patient. CMV disease often remains a life-threatening complication. In addition, studies have suggested a role for this virus as a contributing factor in allograft rejection. In the absence of any preventative therapy, CMV infection occurs in approximately 30 to $75 \%$ of transplant recipients, with an incidence of CMV disease between 8 and $80 \%$. CMV infection may cause indirect effects, including acute and chronic re-infection, increased risk of cardiac complications, diabetes, and even death. Several drugs have been developed and approved for CMV treatment.

Apoptosis is programmed cell death, and is a multicellular animal life activity through gene regulation. Apoptosis mechanisms and the relationship of apoptosis with disease has become a hot topic in the field of biomedical research. Early stages of HCMV infection can block the apoptosis pathway to ensureviral protein synthesis, assembly and replication, resulting in persistent infection. HCMV infection increases the host cell apoptotic loss of cell function, leading to clinical symptoms. HCMV occurs mainly through the endogenous pathway to promote apoptosis [5], and p53 is an apoptosis regulatory factorthat plays an important role.

LEF is an inhibitor of protein kinase activity, and is an immunosuppressive drug used in rheumatoid arthritis and organ transplantation. Many reports have described the benefit of LEF for CMV infection and clinical use $[6,7]$. LEFis currently under discussion for use as an antiviral substance in the clinic, because of its inhibitory effects on several viruses. LEF is cheaper and is easily given orally compared with other antivirals. LEF works via a novel mechanism and also has immunosuppressive properties. This study also found that LEF was effective in CMV infection. Given these considerations we believe that LEF is an exciting new drug for CMV infection. An American study showed that $88 \%$ of kidney transplant recipients suffered CMV infection [8]. Many studies have shownthat the meaningful value of LEF lies in its organ transplantation, bone marrow transplantation and hematopoietic stem cell transplant recipients with CMV infection [9]. In addition, animal experimentsof CMV confirmed that after treatment usingLEF the intracellular levels were significantly decreased by 75 to 99\% [10]. LEF treated active rheumatoid arthritis patients with the HLA-DRB1 gene [11]. Recent studies have shown that LEF can reduce CMV infection of transplant recipients [12]. In addition, rheumatoid arthritis, systemic lupus erythematosus, glomerular diseases, skin diseases and other therapeutic areas also achieved good results. It is encouraging that LEF in the treatment of HCMV infection has also been a widespread concern [13]. The first report stated that LEF has anti-HCMV effects in renal transplant recipients. Recent clinical

Table 1 Inhibitory rate of leflunomide on human embryo lung cells

\begin{tabular}{|c|c|c|c|c|c|}
\hline \multirow[t]{2}{*}{ Group } & \multirow[t]{2}{*}{$n$} & \multirow[t]{2}{*}{24 hours } & \multirow[t]{2}{*}{48 hours } & \multicolumn{2}{|c|}{ Inhibitory rate (\%) } \\
\hline & & & & 24 hours & 48 hours \\
\hline$\overline{\text { Control }}$ & 6 & $0.523 \pm 0.045$ & $0.813 \pm 0.078$ & & \\
\hline LEF1 & 6 & $0.43 \pm 0.062^{*}$ & $0.572 \pm 0.061^{*}$ & 39.7 & 47.1 \\
\hline LEF2 & 6 & $0.568 \pm 0.045^{*}$ & $0.84 \pm 0.028^{*}$ & 21.4 & 30.8 \\
\hline LEF3 & 6 & $0.654 \pm 0.032^{*}$ & $0.932 \pm 0.031^{*}$ & 8.3 & 12.5 \\
\hline
\end{tabular}

$\mathrm{LEF}$, leflunomide. compared with the control; ${ }^{*} \mathrm{p}<0.05,{ }^{*} \mathrm{P}<0.05$. 

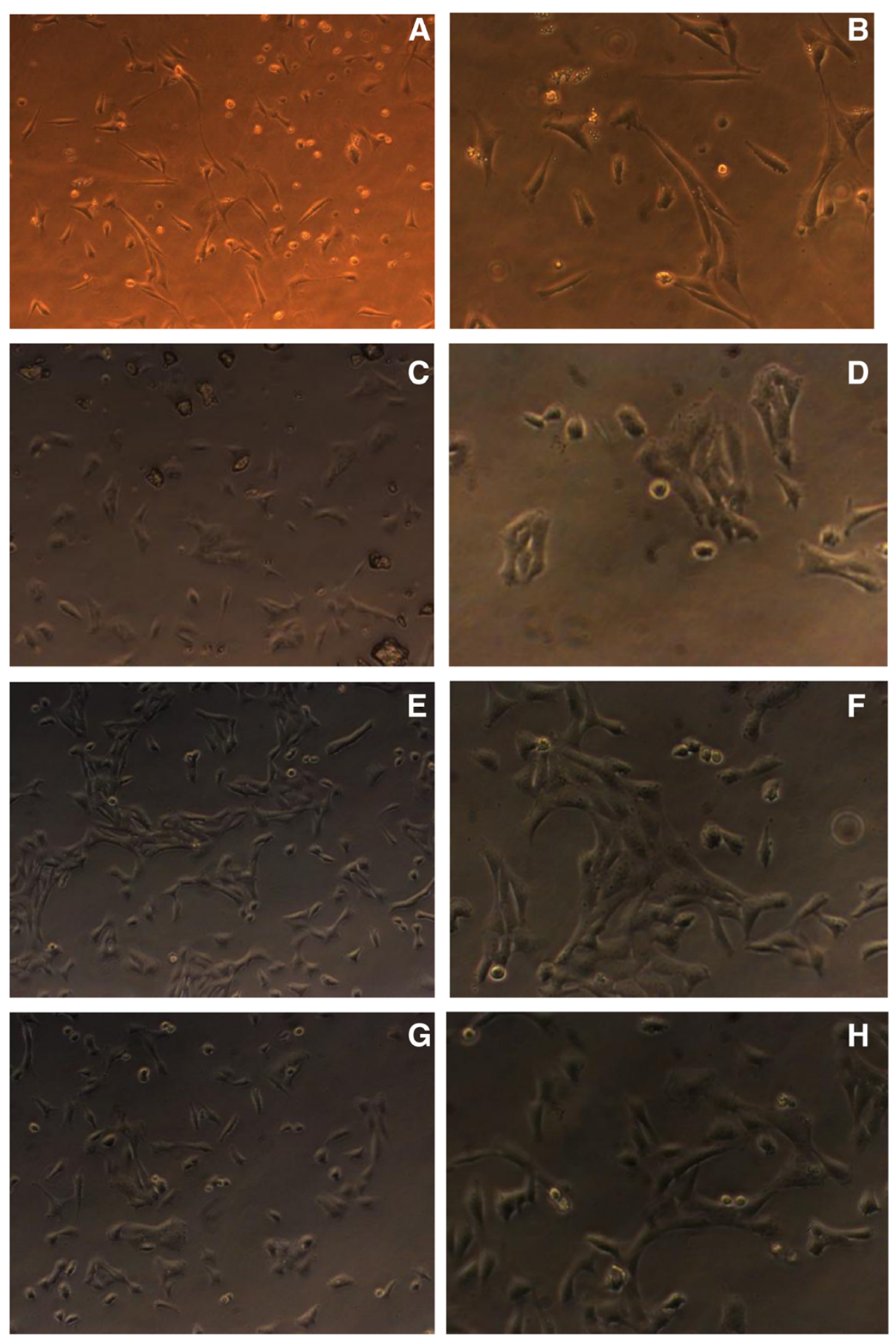

Figure 1 Cell changes in cell morphology at $\mathbf{2 4}$ hours and $\mathbf{4 8}$ hours. (A) Control group (normal human embryonic lung fibroblast at 24 hours, microscope $\times 200$ ). (B) Control group (normal human embryonic lung fibroblast at 48 hours, microscope $\times 400$ ). (C) Human cytomegalovirus (HCMV) group (human embryonic lung fibroblast infected with HCMV at 24 hours, microscope $\times 200$ ). (D) HCMV group (human embryonic lung fibroblast infected with HCMV at 48 hours, microscope $\times 400)$. (E) Ganciclovir (GCV) + HCMV group (GCVadded to the human embryonic lung fibroblast infected with HCMV at 24 hours, microscope $\times 200$ ). (F) GCV + HCMV group (GCV added to the human embryonic lung fibroblast infected with HCMV at 48 hours, microscope $\times 400$ ). (G) Leflunomide (LEF) + HCMV group (LEF added to human embryonic lung fibroblast infected with HCMV at 24 hours, microscope $\times 200$ ). (H) LEF + HCMV group (LEF added to the human embryonic lung fibroblast infected with HCMV at 48 hours, microscope $\times 400)$. 


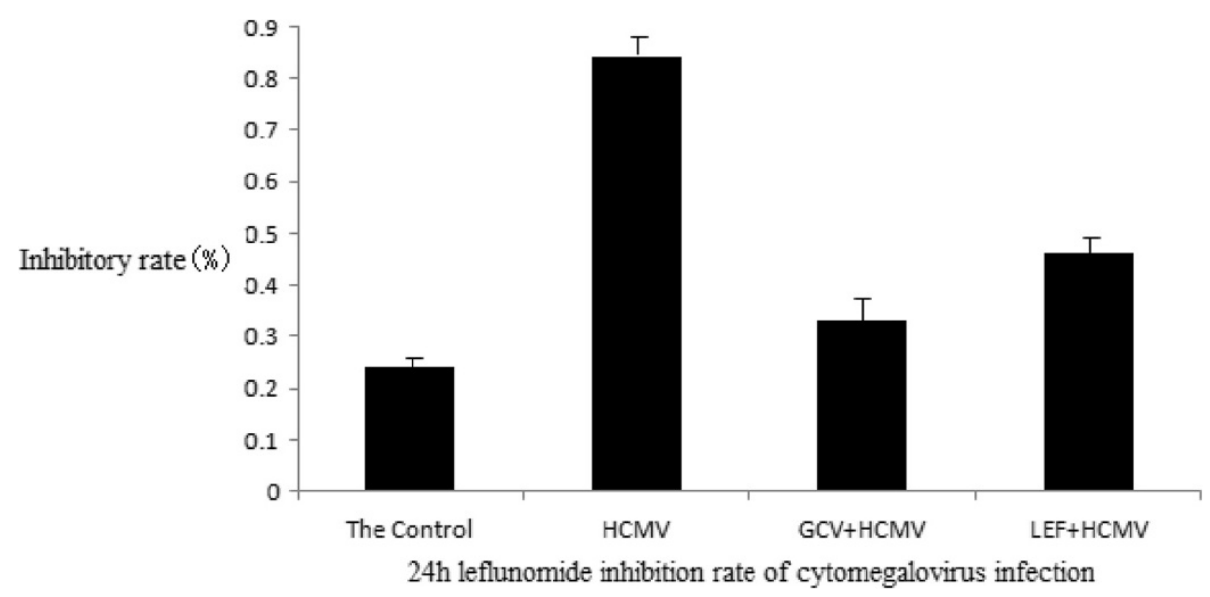

Figure $\mathbf{2}$ Leflunomide inhibition rate of cytomegalovirus infection in each group at $\mathbf{2 4}$ hours.

studies have shown that LEF has a better therapeutic effect on HCMV infection disease after renal transplantation and reduces viremia, promotes the involvement of organ function recovery, and increases sensitivity to GCV in mice with HCMV infection [14-16]. LEF has a significant effect on refractory retinitis after allogeneic bone marrow transplantation in drug-resistant HCMV infection [17-19]. Some studies have shown that the LEF has a good effect on the stubborn resistance of HCMV infection [20,21].

In this study, we observed that cell proliferation was significantly inhibited by HCMV at 24 hours and 48 hours. With increasing HCMV concentrations, the value-added inhibition of cells was significantly decreased compared with the control group, and was statistically significant $(P<0.01)$. Meanwhile, treatment with LEF significantly improved cell proliferation at 24 hours and 48 hours, with statistical significance $(P<0.05)$. The effect of human fetal lung cell proliferation at the different doses of LEF was still significant $(P<0.05)$. In addition, the apoptosis rate of human embryonic lung fibroblasts infected with HCMV increased significantly at 24 hours, 48 hours and 72 hours, and as time goes on the apoptosis rate is increased; compared with the control group it was statistically significant $(P<0.01)$. The apoptosis rate of the HCMV infection group decreased by adding LEF, and was statistically significant $(P<0.05)$. This finding confirmed that LEF is an effective new treatment for CMV infection.

\section{Conclusions}

The search for newer more cost-effective treatments for infectious diseases remains a challenge. In this study, we believe that LEF is an exciting new drug for CMV infection. The future is likely to be first-line or second-line drug treatment for organ transplantation. AIDS immunocompromised patients infected with HCMV also rely on more clinical evidence, but our

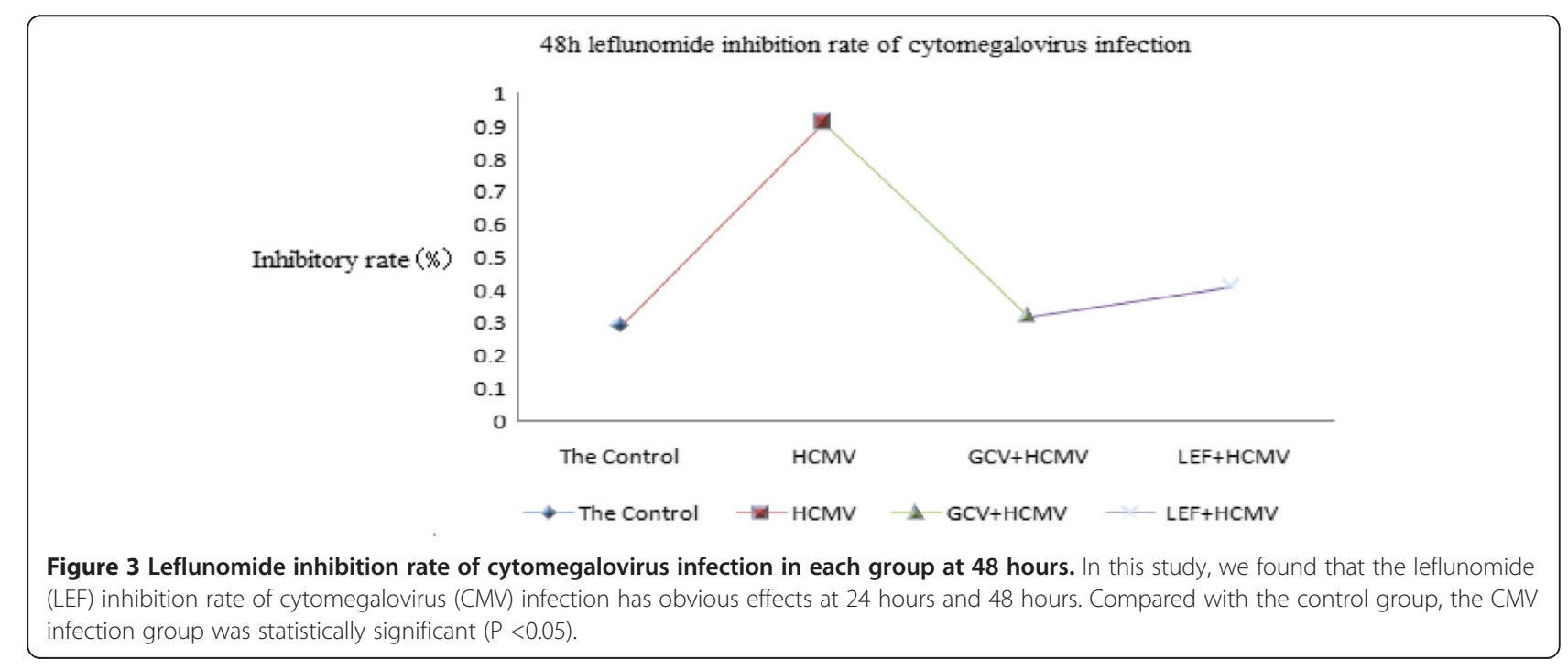




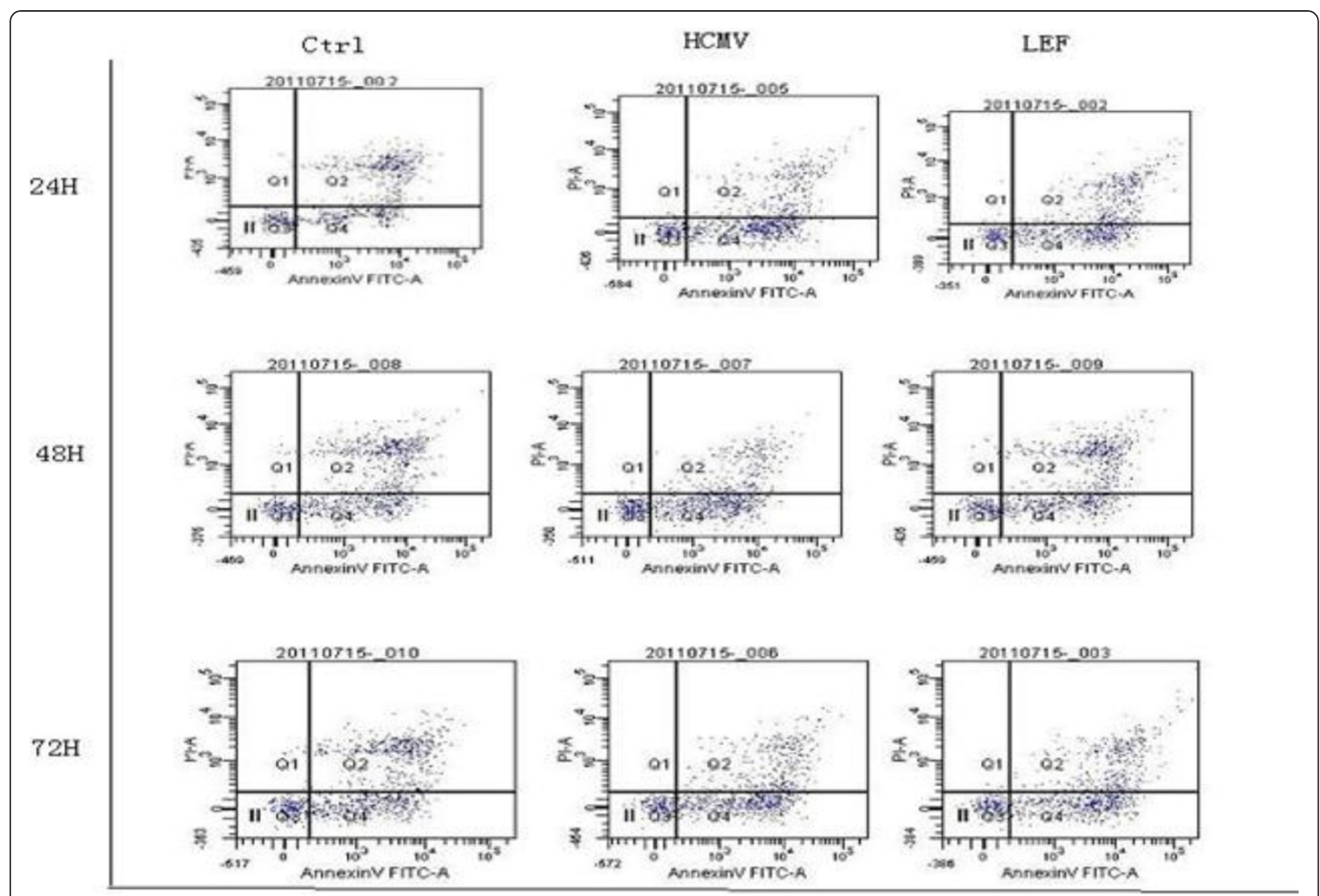

Figure 4 Apoptosis in each group at 24 hours, 48 hours and 72 hours.

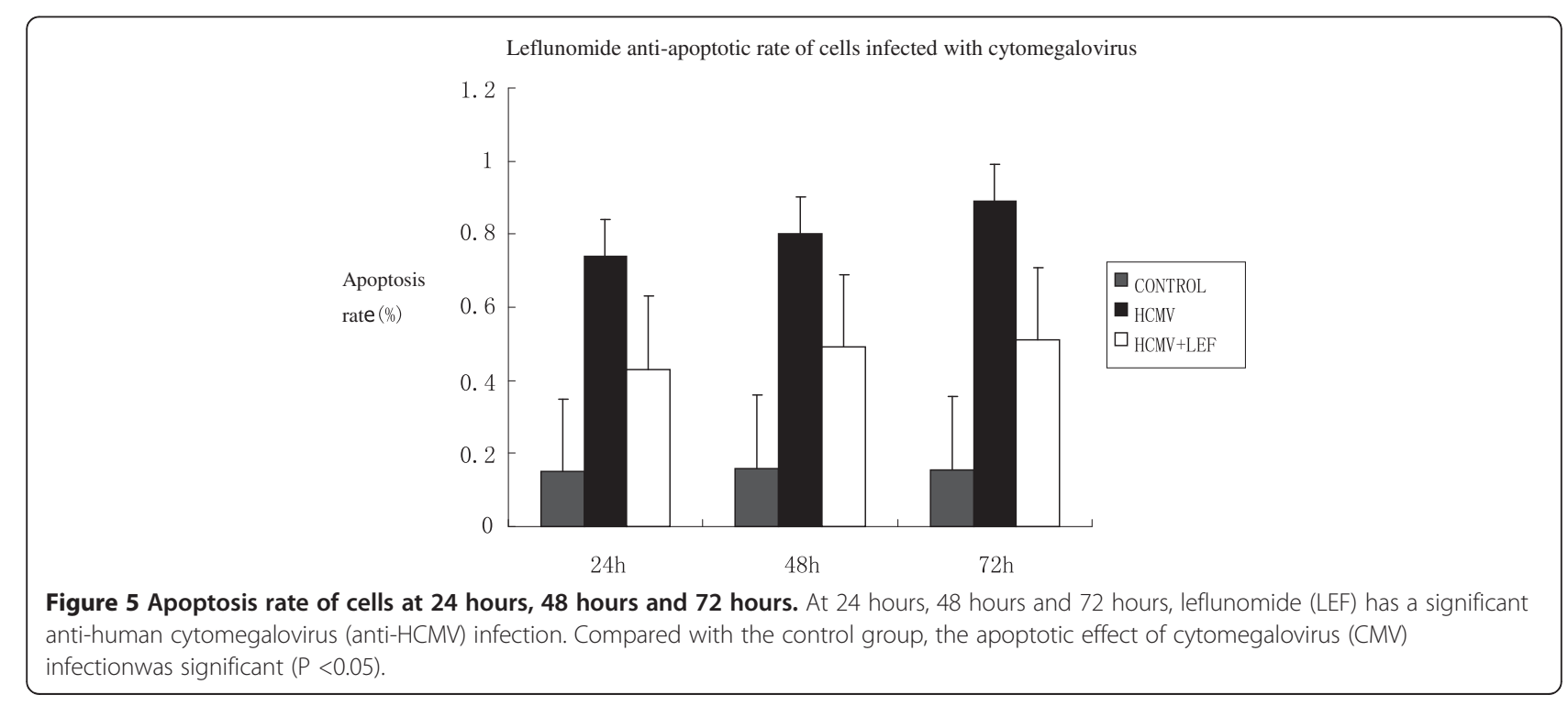


study showed that LEF significantly inhibited HCMV infection-induced apoptosis and proliferation, playing a important role in the treatment of patients infected by HCMV. In this study, we explored the potential usefulness of LEF for CMV infection and found that it to be a cost-effective new treatment for CMV infection that deserves further study.

\section{Abbreviations}

CMV: Cytomegalovirus; GCV: Ganciclovir; HCMV: Human cytomegalovirus; LEF: Leflunomide; MTT: 3-(4,5-dimethylthiazol-2-yl)-2,5-diphenyltetrazolium bromide.

\section{Competing interests}

The authors declare that they have no competing interests.

\section{Authors' contributions}

Z-HS participated in the design of the study. RQ performed the statistical analysis, collected the data and drafted the manuscript. All authors read and approved the final manuscript

\section{Acknowledgements}

The authors thank the Central Laboratory of GuangZhou Women and Children's Medical Center for technique helps. This work was supported by the Natural Science Foundation Project of Guangdong Province (Project No. 9151026003000004). The Grant No. 2012J4100031, Guangzhou City Grant, China, No.012AA02A513,National High Technology Research and Development Program 863, China.

\section{Author details}

'The Department of Pediatric, Allergy, Immunology and Rheumatology, Guangzhou Women and Children's Medicial Center, Guangzhou Medical University and First Clinical Medical College, Jinan University, China. ${ }^{2}$ The Department of Rheumatology, Peking Union Medical College Hospital, Chinese Academy of Medical Sciences, China.

Received: 5 October 2012 Accepted: 10 December 2012

Published: 1 February 2013

\section{References}

1. Cinatal Jr J, Schob M, Doerr HW: Role of tumor cell immune escape mechanisms in cytomegalovirus-mediated oncomodulation. Med Res Rev 2005, 25:167-185.

2. Reuter JD: Cytomegalovirus induces T-cell independent apoptosis in brain during immune deficiency. J Clin Virol 2005, 32:218-223.

3. Goldmacher VS: Cell death suppression by cytomegaloviruses. Apoptosis 2005, 10:251-265.

4. Leger DY, Liagre B, Beneytout JL: Low dose leflunomide activates PI3K/Akt signalling in erythroleukemia cells and reduces apoptosis induced by anticancer agents. Apoptosis 2006, 11:1747-1760.

5. Josephson MA, Williams JW, Chandraker A, Randhawa PS: Polyomavirusassociated nephropathy: update on antiviral strategies. Transpl Infect Dis 2006, 8:95-101.

6. Josephson MA, Jwaid B, Kadambi PV, Meehan SM, Williams JW: Leflunomide in solid organ transplantation and polyoma virus infection. Adv Exp Med Biol 2006, 577:255-265.

7. Ehlert K, Groll AH, Kuehn J, Vormoor J: Treatment of refractory CMVinfection following hematopoietic stem cell transplantation with the combination of fosmet and leflunomide. Klin Padiatr 2006, 218:180-184.

8. Zeng H, Waldman WJ, Yin DP, Knight DA, Shen J, Ma L, Meister GT, Chong AS, Williams JW: Mechanistic study of malononitrileamide FK788 in cardiac transplantation and CMV infection in rats. Transplantation 2005, 79:17-22.

9. Koch S, Larbi A, Ozcelik D, Solana R, Gouttefangeas C, Attig S, Wikby A, Strindhall J, Franceschi C, Pawelec G: Cytomegalovirus infection: a driving force in human T cell immunosenescence. Ann N Y Acad Sci 2007, 1114:23-35

10. Nakajima A, Yamanaka H, Kamatani N: Leflunomide: clinical effectiveness and mechanism of action. Clin Calcium 2003, 13:771-775.
11. Levi ME, Mandava N, Chan LK, Weinberg A, Olson JL: Treatment of multidrug-resistant cytomegalovirus retinitis with systemically administered leflunomide. Transpl Infect Dis 2006, 8(1):38-43.

12. Chong AS, Zeng H, Knight DA, Shen J, Meister GT, Williams JW, Waldman WJ: Concurrent antiviral and immunosuppressive activities of leflunomide invivo. Am J Transp/ 2006, 6:69-75.

13. John GT, Manivannan J, Chandy S, Peter S, Fleming DH, Chandy SJ, Balakrishnan N, Krishnamurthy K, Kirubakaran MG, Jacob CK: A prospective evaluation of leflunomide therapy for cytomegalovirus disease in renal transplant recipients. Transplant Proc 2005, 37:4303-4305.

14. Fitzsimmons WE, First MR: FK778, a synthetic malononitrilamide. Yonse Med J 2004, 45:1132-1135.

15. Avery RK, Bolwell BJ, Yen-Lieberman B, Lurain N, Waldman WJ, Longworth DL, Taege AJ, Mossad SB, Kohn D, Long JR, Curtis J, Kalaycio M, Pohlman B, Williams JW: Use of leflunomide in an allogeneic bone marrow transplant recipient with refractory cytomegalovirus infection. Bone Marrow Transplant 2004, 34:1071-1975.

16. Sarldlart-Direskeneli G, Inanc M, Fresko I, Akkoc N, Dalkilic E, Erken E, Karaaslan Y, Kinikli G, Oksel F, Pay S, Yucel E, Yentür SP, Duymaz-Tozkir J, Yilmaz V, Inanc N, Yazici H, Konice M, Direskeneli H: The role of HLA-DRB1 shared epitope alleles in predicting short-term response to leflunomide in rheumatoid arthritis. Rheumatology (Oxford) 2007, 46:1842-1844.

17. Sudamanam TD, Sahni RD, John GT: Leflunomide: a possible alternative for ganciclovir sensitive and resistant cytomegalovirus infections. Postgrad Med J 2006, 82:313-314.

18. Snydman DR: Leflunomide: a small step forward in meeting the urgent need for treatment of drug-resistant cytomegalovirus infection. Transplantation 2010, 90:362-363.

19. Teschner S, Burst V: Leflunomide: a drug with a potential beyond rheumatology. Immunotherapy 2010, 2:637-650.

20. Eid AJ, Razonable RR: New developments in the management of cytomegalovirus infection after solid organ transplantation. Drugs 2010, 70:965-981.

21. Webel R, Milbradt J, Auerochs S, Schregel V, Held C, Nöbauer K, RazzaziFazeli E, Jardin C, Wittenberg T, Sticht H, Marschall M: Two isoforms of the protein kinase pUL97 of human cytomegalovirus are differentially regulated in their nuclear translocation. J Gen Virol 2011, 92(3):638-649.

doi:10.1186/2047-783X-18-3

Cite this article as: Qi et al:: Leflunomide inhibits the apoptosis of human embryonic lung fibroblasts infected by human cytomegalovirus. European Journal of Medical Research 2013 18:3.

\section{Submit your next manuscript to BioMed Central and take full advantage of:}

- Convenient online submission

- Thorough peer review

- No space constraints or color figure charges

- Immediate publication on acceptance

- Inclusion in PubMed, CAS, Scopus and Google Scholar

- Research which is freely available for redistribution 